\title{
COMPOSIÇÃO CORPORAL E EXIGÊNCIAS LÍQÜIDAS EM ENERGIA E PROTEÍNA PARA GANHO EM PESO DE CHINCHILAS (Chinchilla lanigera) ${ }^{1}$
}

\author{
Body composition and net energy and protein requirements for weight \\ gain of chinchillas (Chinchilla lanigera)
}

\author{
Simone de David Antonio 2 , João Pedro Velho 3 , Paulo Afonso Carvalho ${ }^{4}$, Alfredo Acosta Backes 5 , \\ Luis Maria Bonnecarrère Sanchez ${ }^{6}$, Ione Maria Pereira Haygert Velho ${ }^{7}$
}

\begin{abstract}
RESUMO
Foi avaliada a composição da pele, do corpo sem extremidades, das extremidades corporais e a composição corporal total e estimadas as exigências líquidas de energia e proteína para ganho de peso da espécie Chinchilla lanigera. Foram utilizados 18 animais, tendo sido abatidos seis animais juvenis com 40 dias de idade e 12 animais adultos (seis machos e seis fêmeas) com 750 dias de idade. Foi feito um teste de comparação de médias para as composições das diferentes frações do corpo nas diferentes categorias animal. Foram ajustadas equações logarítmicas da quantidade corporal de proteína, gordura e energia, em função do logaritmo do peso corporal vazio. As exigências líquidas em proteína e energia para ganho de peso foram obtidas por derivação das equações de predição da composição corporal em proteína e energia. Foi verificada uma maior proporção $(\mathrm{P}<0,05)$ de extremidades corporais por parte dos animais juvenis em relação aos adultos. Entretanto, as proporções de pele e de corpo sem extremidades não diferiram $(P>0,05)$ entre as categorias. As quantidades de matéria seca, proteína e gordura corporal, alteraram-se com o avanço da idade. Os animais juvenis apresentaram menor $(\mathrm{P}<0,05)$ percentual de matéria seca e extrato etéreo quando comparados com os adultos. As exigências líquidas de proteína decresceram, enquanto que as exigências energéticas se elevaram com o aumento da idade e peso dos animais.
\end{abstract}

Termos para indexação: Corpo vazio, exigências nutricionais, pele.

\begin{abstract}
The composition of skin, body without extremities (head, feet and tale) and extremities and composition of total body of chinchilla was determined and the net requirements for energy and protein were estimated. Eighteen animals ( 6 males and 6 females, 750 days old and 6 young animals 40 days old) were slaughtered. Mean values for the different body fractions and for animal categories were compared, and logarithmic equations were adjusted for protein, fat and energy content of the body as a function of empty body weight. Net requirements for body weight gain were obtained by derivation of those equations. Higher proportion of extremities was verified in young animals than in adults $(\mathrm{P}<0.05)$ but the proportions of skin and body without extremities was not different between animals categories $(\mathrm{P}>0.05)$ Body contents of dry matter, protein and fat changed with age, young animals had less dry matter and fat than the adults $(\mathrm{P}<0.05)$. Net requirements for protein decreased and for energy increased with increase animal's age and body weight.
\end{abstract}

Index terms: Empty body, nutritional requirements, skin.

(Recebido em 10 de janeiro de 2006 e aprovado em 2 de setembro de 2006)

\section{INTRODUÇÃO}

A Chinchilla lanigera é uma espécie animal exótica no Brasil, que tem sua origem na região dos Andes, América do Sul. A sua criação em cativeiro tem como principal objetivo à produção de peles, tendo despertado o interesse de muitos criadores. É uma exploração animal relativamente nova, com aproximadamente 75 anos no mundo e 35 anos no Brasil. Entretanto, a criação brasileira como atividade econômica só obteve crescimento significativo na última década motivada, principalmente, pela grande demanda de peles no mercado internacional aliado á uma baixa oferta do produto. Segundo Asbrachila (2005), a produção

\footnotetext{
${ }^{1}$ Projeto desenvolvido pela Universidade Federal de Santa Maria/UFSM e ASBRACHILA.

${ }^{2}$ Zootecnista, M. Sc., Zootecnista do Departamento de Zootecnia - Universidade Federal de Santa Maria/UFSM - Campus Universitário - $97105-900$ Santa Maria, RS - simoneda@smail.ufsm.br

${ }^{3}$ Zootecnista, M. Sc., Programa de Pós-graduação em Zootecnia - Universidade Federal do Rio Grande do Sul/UFRGS - Av. Bento Gonçalves, 7712 91540-000 - Porto Alegre, RS - Bolsista CNPq - velhojp@yahoo.com.br

${ }^{4}$ Zootecnista, Dr. Sc. , Professor Adjunto - Universidade Estadual do Rio Grande do Sul/UFRGS - Campus Regional III - Rua Nestor Ribas Fritsch, 1111 Bairro Esperança - 98200-000 - Ibirubá, RS - pac@mail.ufsm.br

${ }^{5}$ Zootecnista, Dr. Sc., Professor Adjunto - Universidade Federal de Sergipe -Departamento de Engenharia Agronômica/DEA - Centro de Ciências Sociais e da Saúde/CCBS - Cidade Universitária - Prof. José Aloísio de Campos - Bairro Jardim Rosa Elze, s/n - 49100-000 - São Cristóvão, SE abackes@ufs.br

${ }^{6}$ Engenheiro Agrônomo, Ph. D. - Professor Titular do Departamento de Zootecnia - Universidade Federal de Santa Maria/UFSM - Campus Universitário - 97105-900 - Santa Maria, RS - bonne@ccr.ufsm.br

${ }^{7}$ Zootecnista, M. Sc., Programa de Pós-graduação em Zootecnia - Universidade Federal do Rio Grande do Sul/UFRGS - Av. Bento Gonçalves, 7712 91540-000 - Porto Alegre, RS - Bolsista CAPES - imphaygert@yahoo.com.br
} 
mundial de peles de chinchila atende, atualmente, apenas cerca de $50 \%$ de sua demanda. Todavia, este é um mercado bastante exigente quanto à qualidade do produto a ser comercializado.

Para desenvolver um sistema de produção eficiente, tanto biologicamente como economicamente, a nutrição é um aspecto importante a se considerar, independente da espécie explorada. Entretanto, a nutrição de chinchilas nas criações existentes no Brasil é realizada através de conhecimentos empíricos adquiridos pela experiência dos pioneiros nesta atividade, carecendo de dados concretos originários de pesquisas científicas brasileiras e/ou mundiais.

O cálculo das exigências nutricionais para crescimento requer informações da composição química dos tecidos depositados e da eficiência com que os nutrientes ingeridos são convertidos nesses tecidos (SEARLE et al., 1972). Para se estimarem as exigências nutricionais é fundamental o conhecimento da composição corporal e do ganho em peso, uma vez que estas características estão diretamente relacionadas.

Existe uma carência de informações científicas a respeito de chinchilas, todavia, acredita-se que a espécie siga os mesmos padrões de crescimento verificado com outras espécies de animais domésticos, com algumas peculiaridades.

Conforme Berg \& Butterfield (1976), a maturidade animal é refletida por aumento na proporção de gordura e decréscimos na proporção de água, proteína e minerais no corpo. Quando os animais saem da fase de crescimento e atingem a maturidade, verifica-se um incremento nos requerimentos energéticos e uma redução nos requerimentos protéicos, conforme o aumento de peso e mudanças ocorridas no ganho de peso corporal (ARC, 1980).

A proteína e a energia são de fundamental importância como nutriente e combustível do organismo animal. Além disso, quando ingeridos em quantidades superiores aos requerimentos nutricionais de mantença, estes compostos são depositados como tecidos no corpo dos animais, principalmente sob a forma de músculo e gordura.

Objetivou-se com este estudo foi verificar o padrão de crescimento desta espécie de animal doméstico (Chinchilla lanigera), bem como determinar a composição corporal e estimar as exigências líquidas em energia e proteína para ganho de peso, visando o estabelecimento de parâmetros nutricionais, pouco conhecidos para a referida espécie.

\section{MATERIAL E MÉTODOS}

Foram utilizados 18 animais da espécie Chinchilla lanigera, sendo seis animais juvenis com 40 dias de idade e 12 animais adultos (seis machos e seis fêmeas) com 750 dias de idade. Os animais foram alimentados com cubos de feno de alfafa e ração balanceada peletizada $(21 \%$ de proteína bruta), em um sistema de criação convencional (gaiolas geminadas com seis fêmeas e um macho no corredor = uma família) sistema este, usual entre os criadores associados à ASBRACHILA. Os animais foram abatidos por destroncamento da base do crânio, conforme metodologia descrita por Merçon (1989), às oito horas da manhã, sem jejum prévio. Logo após, foram pesados, considerando-se este como peso ao abate.

Foram separadas as frações: pele, corpo sem extremidades (que incluiu carcaça, órgãos internos e cabeça) e extremidades corporais (que incluiu patas, orelhas e cauda). Cada uma destas frações foi pesada, moída e analisada individualmente, exceto no caso dos juvenis em que, devido ao baixo peso dos animais, não foi possível analisá-las individualmente, compondo uma única amostra por animal. As porções do trato digestivo foram pesadas cheias e vazias, obtendo por diferença o peso do conteúdo gastrintestinal. O peso de corpo vazio (PCVZ) de cada animal abatido foi obtido por diferença entre o peso ao abate e o peso do conteúdo gastrintestinal.

As amostras foram pré-desengorduradas com éter de petróleo, conforme técnica descrita por Kock \& Preston (1979). As determinações de matéria seca, proteína bruta, extrato etéreo e cinzas foram realizadas segundo metodologias descritas por Silva (1998).

O conteúdo corporal de energia foi obtido a partir dos conteúdos de proteína e gordura retidos no corpo vazio e dos respectivos equivalentes calóricos, segundo a equação proposta pelo Agricultural Research Council ARC (1980): $C E=5,6405 X+9,3939 Y$, em que CE = conteúdo de energia (Kcal), $\mathrm{X}=$ proteína corporal $(\mathrm{g})$ e $\mathrm{Y}=$ gordura corporal (g).

Para determinação dos conteúdos de proteína, gordura e energia retidos no corpo dos animais foram adotadas equações de regressão do logaritmo do conteúdo corporal destes nutrientes em função do logaritmo do peso de corpo vazio (PCVZ), de acordo com o modelo proposto pelo ARC (1980): $\log _{10} y=a+b * \log _{10} x+\varepsilon$, em que $\log _{10}$ $\mathrm{y}=$ logaritmo de base 10 da quantidade do nutriente retido no corpo vazio, $a=$ intercepto, $b=$ coeficiente de regressão do logaritmo do conteúdo de proteína, gordura e energia retido no PCVZ, $\log _{10} \mathrm{x}=\log$ aritmo de base 10 do PCVZ e $\varepsilon=$ erro aleatório. 
Derivando-se as equações logarítmicas de estimativa do conteúdo corporal de proteína, gordura e energia, foram obtidas as equações de predição dos requerimentos líquidos de proteína e energia para ganho de $1 \mathrm{~g}$ de corpo vazio (GPCVZ), do tipo: $\hat{\mathrm{Y}}=\mathrm{b} * 10^{\mathrm{a}} *$ PCVZ ${ }^{(b-1)}$, em que $\hat{Y}=$ exigência líquida de proteína $(\mathrm{mg} /$ g GPCVZ) ou energia (Kcal/g GPCVZ); b = coeficiente de regressão do logaritmo do conteúdo de proteína e energia em função do logaritmo de PCVZ e a = intercepto.

Para conversão do peso vivo (PV) em PCVZ, na faixa de PV adotada entre 100 e $700 \mathrm{~g}$ utilizou-se a equação obtida por regressão do PCVZ dos 18 animais experimentais abatidos, em função do peso ao abate dos mesmos. Foi determinado um fator de conversão (FC) obtido pelo quociente do PV em função do PCVZ, e este FC foi utilizado para converter o GPCVZ em ganho de peso vivo (GPV).

Os dados foram submetidos à análise de variância e as médias comparadas pelo teste Tukey ao nível de 5\% de significância. Foi realizado um estudo de regressão linear simples para estimativa das características avaliadas. Todas as análises estatísticas foram realizadas utilizando-se o programa Statistical Analysis System - SAS Institute (1996).

\section{RESULTADOS E DISCUSSÃO}

As proporções de corpo sem extremidade, pele e extremidades corporais de machos adultos, fêmeas adultas e animais juvenis são mostradas na Tabela 1. Os animais juvenis apresentaram $(\mathrm{P}<0,05)$ maior proporção de extremidades corporais em relação aos animais adultos. Entretanto, não diferiram $(\mathrm{P}>0,05)$ quanto à proporção de pele e de corpo sem extremidades. De acordo com Huidobro \& Villapadierna (1992), os animais seguem um modelo de desenvolvimento disto-proximal em que as extremidades distais são mais precoces, apresentando uma maior proporção do seu peso maduro antes que o restante do corpo. Tal relato pode justificar, em parte, o fato de os animais juvenis apresentarem maior proporção de extremidades corporais do que os animais adultos.

Conforme Sanchez (1976), a transição do nascimento até a maturidade dos animais envolve não somente um incremento do tamanho corporal, mas também alterações na forma, função e proporção relativa dos diferentes componentes corporais.

Os valores médios de composição química do corpo como um todo e das frações corpo sem extremidades, pele e extremidades corporais são mostrados na Tabela 02. Os animais juvenis apresentaram $(\mathrm{P}<0,05)$ maiores proporções de água e extrato etéreo na matéria natural do corpo como um todo, do que os animais adultos. Da mesma forma, os juvenis apresentaram $(\mathrm{P}<0,05)$ maiores proporções de matéria mineral e proteína e menor proporção de extrato etéreo na matéria seca do corpo como um todo, do que os adultos. A composição corporal observada no presente estudo concorda com relatos de Berg \& Butterfield (1976), Di Marco (1994) e Verde (1996), os quais verificaram o mesmo padrão de desenvolvimento, embora com outras espécies animais. Segundo os autores referenciados acima, animais mais jovens são mais ricos em água e mais pobres em gordura, em que as concentrações de água, proteína e minerais decrescem com a idade e com a engorda. Tal constatação é um indicativo de que a espécie Chinchilla lanigera_apresenta o mesmo comportamento de crescimento e desenvolvimento do que os demais animais domésticos até então estudados.

A composição química do corpo como um todo, do corpo sem extremidades, da pele e das extremidades corporais (Tabela 2) não diferiram $(\mathrm{P}>0,05)$ entre animais adultos (machos e fêmeas). Exceção foi verificada com relação à $\mathrm{MM}$ e EE da pele. A maior concentração de MM observada para as fêmeas deve-se ao maior tempo de contato destas com o pó de mármore (necessário para os animais realizarem a higiene da sua pele), ocasionando resíduo deste mineral na pele após o abate. Da mesma

TABELA 1 - Valores percentuais médios do corpo sem extremidades, pele e extremidades corporais de chinchilas adultos (machos e fêmeas) e de animais juvenis, expressos na matéria natural.

\begin{tabular}{lcccc}
\hline \multirow{2}{*}{ Frações corporais $(\%)$} & \multicolumn{3}{c}{ Categoria } & \multirow{2}{*}{ P $>\mathbf{F}^{*}$} \\
\cline { 2 - 4 } & Macho & Fêmea & Juvenis & 0,5236 \\
Corpo sem extremidades & 78,220 & 79,292 & 78,031 & 0,1050 \\
Pele & 17,018 & 14,967 & 14,267 & 0,0001 \\
Extremidades corporais & $4,461^{\mathrm{b}}$ & $5,740^{\mathrm{b}}$ & $7,703^{\mathrm{a}}$ & 0 \\
\hline
\end{tabular}

* Teste Tukey em que a, b na linha $(\mathrm{P}<0,05)$. 
forma, supõe-se que devido aos machos não terem sido submetidos a higienização com pó de mármore, a pele destes possa ter acumulado resíduos gordurosos promovendo uma maior concentração de EE na pele destes em relação à pele das fêmeas.

Os valores da composição em proteína e gordura no corpo de chinchilas adultos, observado neste experimento, são inferiores aos valores observados por Gomes \& Ferreira (1999) na carcaça de coelhos, trabalhos específicos da espécie não foram localizados.

Os parâmetros das equações logarítmicas da quantidade de proteína, gordura e energia corporal, em função do logaritmo do PCVZ são apresentados na Tabela 3. Foi observado um efeito linear significativo da regressão $(\mathrm{P}<0,01)$ para as equações relativas aos conteúdos corporais de proteína, gordura e energia. Os $\mathrm{R}^{2}$ foram elevados, o que demonstra o bom ajuste das equações ao modelo matemático adotado. Tal fato indica que variações nas composições corporais em proteína, gordura e energia ocorreram na mesma proporção que a variação do peso de corpo vazio dos animais.

Observa-se (Tabela 3) que o coeficiente (b) da equação logarítmica da proteína apresentou-se inferior a uma unidade, indicando que o conteúdo protéico do corpo decresceu proporcionalmente ao aumento do peso corporal das chinchilas. No entanto, os coeficientes das equações de gordura e de energia foram superiores a uma unidade indicando uma elevação da composição energética com o aumento do peso corporal. Tal constatação é concordante com Di Marco (1994) o qual descreve que o animal ganha peso pela acumulação de tecidos, segundo padrões de prioridade. Conforme aumenta o peso corporal, ocorre a desaceleração do crescimento muscular, acontecendo o contrário com o tecido adiposo. Neste processo, os

TABELA 2 - Valores percentuais médios de matéria seca (MS), matéria mineral (MM), proteína bruta (PB) e extrato etéreo (EE) no total corporal, corpo sem extremidades, pele e extremidades corporais de chinchilas, em diferentes categorias animais, expressos na matéria natural e na matéria seca.

\begin{tabular}{|c|c|c|c|c|c|c|c|c|}
\hline \multirow{2}{*}{$\begin{array}{c}\text { Frações } \\
(\%)\end{array}$} & \multicolumn{4}{|c|}{ Matéria natural } & \multicolumn{4}{|c|}{ Matéria seca } \\
\hline & Macho & Fêmea & Juvenis & $\mathbf{P}>\mathbf{F}$ & Macho & Fêmea & Juvenis & $\mathbf{P}>\mathbf{F}^{*}$ \\
\hline \multicolumn{9}{|c|}{ Total corporal } \\
\hline MS & $49,515^{\mathrm{a}}$ & $42,643^{\mathrm{a}}$ & $29,202^{b}$ & 0,0006 & 100 & 100 & 100 & -- \\
\hline MM & 4,438 & 5,333 & 4,444 & 0,1589 & $9,216^{\mathrm{b}}$ & $13,069^{\mathrm{ab}}$ & $16,311^{\mathrm{a}}$ & 0,0108 \\
\hline PB & 15,942 & 18,166 & 17,744 & 0,1095 & $33,325^{\mathrm{b}}$ & $44,308^{\mathrm{b}}$ & $64,768^{\mathrm{a}}$ & 0,0001 \\
\hline EE & $29,135^{\mathrm{a}}$ & $19,144^{\mathrm{a}}$ & $5,552^{\mathrm{b}}$ & 0,0009 & $57,458^{\mathrm{a}}$ & $42,622^{\mathrm{a}}$ & $18,921^{\mathrm{b}}$ & 0,0002 \\
\hline \multicolumn{9}{|c|}{ Corpo sem extremidades } \\
\hline MS & 47,021 & 40,321 & -- & 0,2378 & 100 & 100 & -- & -- \\
\hline MM & 3,943 & 4,347 & -- & 0,4150 & 11,278 & 14,593 & -- & 0,1674 \\
\hline PB & 11,129 & 12,858 & -- & 0,0670 & 32,184 & 43,433 & -- & 0,0995 \\
\hline EE & 21,037 & 14,033 & -- & 0,1899 & 56,537 & 41,975 & -- & 0,0967 \\
\hline \multicolumn{9}{|c|}{ Pele } \\
\hline MS & 67,098 & 59,725 & -- & 0,0592 & 100 & 100 & -- & -- \\
\hline MM & $0,230^{\mathrm{b}}$ & $0,637^{\mathrm{a}}$ & -- & 0,0241 & $2,382^{b}$ & $8,100^{a}$ & -- & 0,0368 \\
\hline PB & 3,469 & 3,722 & -- & 0,4079 & 33,153 & 45,120 & -- & 0,0922 \\
\hline EE & 7,389 & 4,262 & -- & 0,0740 & $64,465^{\mathrm{a}}$ & $46,780^{\mathrm{b}}$ & -- & 0,0475 \\
\hline \multicolumn{9}{|c|}{ Extremidades corporais } \\
\hline MS & 52,577 & 52,661 & -- & 0,9240 & 100 & 100 & -- & -- \\
\hline MM & 0,806 & 1,137 & -- & 0,7031 & 9,216 & 13,069 & -- & 0,0872 \\
\hline PB & 1,343 & 1,586 & -- & 0,1045 & 33,325 & 44,308 & -- & 0,0940 \\
\hline $\mathrm{EE}$ & 0,642 & 0,762 & -- & 0,3343 & 57,458 & 42,622 & -- & 0,0770 \\
\hline
\end{tabular}

* Teste Tukey em que a, b na linha $(\mathrm{P}<0,05)$. 
componentes químicos do corpo variam paralelamente à composição física corporal (VÉRAS, 2000).

A regressão ajustada para estimar o $\mathrm{PCVZ}$ a partir do PV apresentou comportamento linear $(\mathrm{P}<0,01)$ obtendo-se a equação PCVZ = -5,006 + 0,927 PV $\left(\mathrm{R}^{2}=99,91\right)$. $\mathrm{O}$ elevado valor do coeficiente de determinação demonstra o bom ajuste da equação, com baixa dispersão de pontos em torno da linha de regressão. A faixa de PV adotada variou de 100 a $700 \mathrm{~g}$, com respectivos PCVZ variando de 87,74 a $644,24 \mathrm{~g}$.

$\mathrm{Na}$ Tabela 4, são mostrados os conteúdos de proteína, gordura e energia por grama de peso corporal vazio (PCVZ), composição em gordura e exigências líquidas em proteína e energia por grama de ganho de peso de corpo vazio (GPCVZ) e ganho de peso vivo (GPV).

Ocorreu diminuição do conteúdo de proteína no PCVZ com o aumento de peso dos animais e, em consequiência, as exigências líquidas em proteína para
GPCVZ e GPV decresceram. Para os conteúdos de gordura e energia foi verificado o inverso. Com a elevação do peso ocorreu um incremento nos conteúdos de gordura e energia no PCVZ, aumentando as exigências líquidas em energia, à medida que os animais tornaram-se mais pesados.

As observações verificadas neste trabalho estão de acordo com tabelas de exigências nutricionais de coelhos, como demonstrado por Andriguetto et al. (1983), os quais consideram as exigências apresentadas como ideais para as condições brasileiras. Estes autores afirmam que animais jovens (quatro semanas de vida) necessitam de menos energia (2.400 vs $2.600 \mathrm{Kcal} \mathrm{EM})$ do que animais adultos. Segundo Normas... (1992), coelhos em crescimento possuem uma exigência de energia de $2.500 \mathrm{Kcal}$ EM. Porém, na fase adulta esta exigência passa a ser de $2.600 \mathrm{Kcal}$ EM.

De acordo com Cheeke (1991), coelhos com quatro a doze semanas de vida apresentam uma exigência protéica de $15 \%$, enquanto que para animais adultos não lactantes

TABELA 3 - Parâmetros das equações de regressão do logaritmo dos conteúdos de proteína, gordura e energia no corpo vazio, em função do logaritmo do peso de corpo vazio de chinchilas até os 750 dias de vida.

\begin{tabular}{lcccc}
\hline \multirow{2}{*}{ Fração } & \multicolumn{2}{c}{ Parâmetros } & \multirow{2}{*}{$\mathbf{R}^{\mathbf{2}}(\boldsymbol{\%})$} & \multirow{2}{*}{$\mathbf{P}>\mathbf{F}$} \\
\cline { 2 - 3 } & Intercepto (a) & Coeficiente $(\boldsymbol{\beta})$ & & 0,0001 \\
Proteína $(\mathrm{g})$ & $-0,638821$ & 0,949278 & 97,69 & 0,0001 \\
Gordura $(\mathrm{g})$ & $-3,515206$ & 2,060200 & 93,27 & 0,0001 \\
Energia $(\mathrm{kcal})$ & $-0,918061$ & 1,524594 & 96,57 & 0,0001 \\
\hline
\end{tabular}

TABELA 4 - Conteúdo de proteína, gordura e energia por grama de peso de corpo vazio (PCVZ), composição em gordura e exigências liquidas de proteína e energia por grama de ganho de peso de corpo vazio (GPCVZ) e por grama de ganho de peso vivo (GPV) de chinchilas até os 750 dias de vida.

\begin{tabular}{|c|c|c|c|c|c|c|c|c|}
\hline \multicolumn{2}{|c|}{ Peso Vivo (g) } & 100 & 200 & 300 & 400 & 500 & 600 & 700 \\
\hline \multicolumn{2}{|l|}{ PCVZ (g) } & 87,74 & 180,49 & 273,24 & 365,99 & 458,74 & 551,49 & 644,24 \\
\hline \multirow{3}{*}{$\begin{array}{c}\text { Proteína } \\
(\mathrm{mg} / \mathrm{g})\end{array}$} & PCVZ & 0,183 & 0,176 & 0,173 & 0,170 & 0,168 & 0,167 & 0,165 \\
\hline & GPCVZ & 0,174 & 0,167 & 0,164 & 0,162 & 0,160 & 0,158 & 0,157 \\
\hline & GPV & 0,152 & 0,151 & 0,149 & 0,148 & 0,147 & 0,146 & 0,145 \\
\hline \multirow{3}{*}{$\begin{array}{c}\text { Gordura } \\
(\mathrm{mg} / \mathrm{g})\end{array}$} & PCVZ & 0,035 & 0,075 & 0,117 & 0,159 & 0,202 & 0,246 & 0,290 \\
\hline & GPCVZ & 0,072 & 0,155 & 0,241 & 0,328 & 0,417 & 0,507 & 0,598 \\
\hline & GPV & 0,063 & 0,140 & 0,219 & 0,301 & 0,383 & 0,466 & 0,551 \\
\hline \multirow{3}{*}{$\begin{array}{l}\text { Energia } \\
(\mathrm{Kcal} / \mathrm{g})\end{array}$} & PCVZ & 1,26 & 1,84 & 2,29 & 2,67 & 3,01 & 3,31 & 3,59 \\
\hline & GPCVZ & 1,92 & 2,81 & 3,49 & 4,07 & 4,58 & 5,05 & 5,48 \\
\hline & GPV & 1,69 & 2,54 & 3,18 & 3,73 & 4,21 & 4,64 & 5,04 \\
\hline
\end{tabular}


e/ou gestantes a necessidade protéica decresce para $13 \%$. Andriguetto et al. (1983) reportam em 18 e $16 \%$ as exigências protéicas de coelhos jovens e adultos, respectivamente. Tal comportamento ocorre em função de que animais jovens apresentam um elevado desenvolvimento muscular, necessitando de um adequado aporte de proteína, sendo este um nutriente fundamental na fase de crescimento.

O padrão de desenvolvimento corporal, assim como, a composição do ganho de peso corporal e ganho de peso vivo observados no presente estudo são concordantes com dados encontrados na literatura para outras espécies de animais, como, por exemplo, ovinos e bovinos. Todavia, não foram encontrados trabalhos de determinação da composição corporal e requerimentos nutricionais de chinchilas para uma comparação mais específica, justificando a realização deste e de futuros trabalhos nesta área.

\section{CONCLUSÕES}

A composição corporal em matéria seca, matéria mineral, proteína bruta e gordura de animais da espécie Chinchilla lanigera, altera-se com o incremento de peso e idade.

À medida que aumenta o peso dos animais ocorre decréscimo no requerimento líquido em proteína e acréscimo no requerimento em energia para ganho em peso.

Recomenda-se a realização de mais trabalhos de determinação da composição corporal e requerimentos nutricionais de Chinchilla lanigera, a fim de se obter um maior número de informações sobre esta espécie animal.

\section{REFERÊNCIAS BIBLIOGRÁFICAS}

AGRICULTURAL RESEARCH COUNCIL. The nutrient requirements of ruminant livestock. London, 1980. 351 p.

ANDRIGUETTO, J. M.; PERLY, L.; MINARDI, I. Nutrição animal. 3. ed. São Paulo: Nobel, 1983. v. 2, 425 p.

ASSOCIAÇÃO SUL BRASILEIRA DE CRIADORES DE CHINCHILA. Manuais de criação. Disponível em: http:// 'www.chinchila.com.bíl>. Acesso em: 4 ago. 2005.

BERG, R. T.; BUTTERFIELD, R. M. New concepts of cattle growth. New York: Sydney University, 1976. 240 p.

CHEEKE, P. R. Applied animal nutrition feeds and feeding [S.1.]: Prentice Hall, 1991. 503 p.
DI MARCO, O. N. Crecimiento y respuesta animal. Balcarse: Asociación Argentina de Producción Animal, 1994. 129 p.

GOMES, A. V. da C.; FERREIRA, W. M. Composição química corporal e eficiência alimentar de coelhos alimentados com diferentes dietas. In: REUNIÃO ANUAL DA SOCIEDADE BRASILEIRA DE ZOOTECNIA, 36., 1999, Porto Alegre, RS. Anais... Porto Alegre: SBZ, 1999. CD-ROM.

HUIDOBRO, F. R.; VILLAPADIERNA, A. Estudios sobre crecimiento y desarrollo en corderos de raza Manchega. 1992. 191 f. Tesis (Doctoral) - Universidad Complutense, Madrid, 1992.

KOCK, S. W.; PRESTON, R. L. Estimation of bovine carcass composition by the urea dilution technique. Journal of Animal Science, Champaign, v. 48, n. 2, p. 319-327, 1979.

MERÇON, M. Primeira criação racional de chinchilla. São Paulo: [s.n.], 1989. 265 p.

NORMAS e padrões de nutrição e alimentação animal. São Paulo: Nobel, 1992. 146 p.

SANCHEZ, L. M. B. Food intake of sheep as affected by diet and body composition. 1976. $250 \mathrm{f}$. Thesis (Ph.D.) University of Aberdeen, Aberdeen, 1976.

SAS INSTITUTE. SAS user's guide: statistics. Version 6.11. Cary, 1996.

SEARLE, T. W.; GRAHAM, N.; CALLAGHAN, M. Growth in sheep. Journal of Agricultural Science, Champaign, v. 79, p. 371-382, 1972.

SILVA, D. J. Análise de alimentos: métodos químicos e biológicos. Viçosa: UFV, 1998. 165 p.

VÉRAS, A. S. C. Consumo, digestibilidade, composição corporal e exigências nutricionais de bovinos nelore alimentados com rações contendo diferentes níveis de concentrado. 2000. 166 f. Tese (Doutorado em Zootecnia) Universidade Federal de Viçosa, Viçosa, 2000.

VERDE, L. S. Crescimento e crescimento compensatório na produção animal. Santa Maria: UFSM, 1996. 23 p.

Ciênc. agrotec., Lavras, v. 31, n. 2, p. 479-484, mar./abr., 2007 